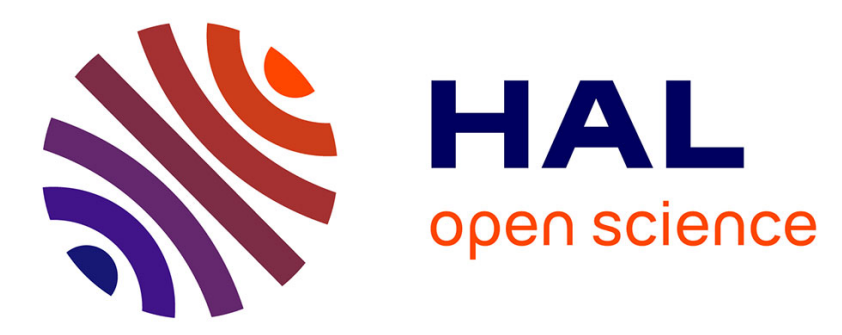

\title{
Auto-ignition of near-ambient temperature H2/air mixtures during flame-vortex interaction
}

Adam Steinberg, Ketana Teav, Sina Kheirkhah, Chaimae Bariki, Fabien Thiesset, Christian Chauveau, Fabien Halter

\section{- To cite this version:}

Adam Steinberg, Ketana Teav, Sina Kheirkhah, Chaimae Bariki, Fabien Thiesset, et al.. Autoignition of near-ambient temperature H2/air mixtures during flame-vortex interaction. Proceedings of the Combustion Institute, 2019, 37 (2), pp.2425-2432. 10.1016/j.proci.2018.08.028 . hal-01931173

\section{HAL Id: hal-01931173 \\ https://hal.science/hal-01931173}

Submitted on 13 Sep 2019

HAL is a multi-disciplinary open access archive for the deposit and dissemination of scientific research documents, whether they are published or not. The documents may come from teaching and research institutions in France or abroad, or from public or private research centers.
L'archive ouverte pluridisciplinaire HAL, est destinée au dépôt et à la diffusion de documents scientifiques de niveau recherche, publiés ou non, émanant des établissements d'enseignement et de recherche français ou étrangers, des laboratoires publics ou privés. 


\title{
Auto-ignition of near-ambient $\mathrm{H}_{2}$ /air mixtures during flame-vortex interaction
}

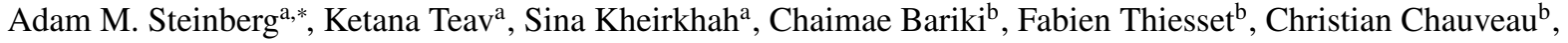 \\ Fabien Halter ${ }^{\mathrm{b}}$ \\ ${ }^{a}$ University of Toronto, Toronto, ON, Canada, M3H 5 T6 \\ ${ }^{b}$ CNRS ICARE, Orléans, France, 45072
}

\begin{abstract}
This paper demonstrates auto-ignition in reactants at approximately $350 \mathrm{~K}$, upstream of curved $\mathrm{H}_{2} /$ air flame surfaces during flame/vortex interaction. Temperature fields were measured using laser Rayleigh scattering during head-on interactions of toroidal-vortices with stagnation flames. Repeatable ignition occurred along the ring of the vortex slightly towards the center - when it was approximately $1 \mathrm{~mm}$ upstream of the wrinkled flame surface. The resultant outwardly propagating toroidal flame led to approximately twice the volumetric heat release rate over the duration of the interaction. The ignition occurred in a region of low fluid dynamic strain rate that was farther from the flame than the region of maximum vorticity. Evidence of additional ignition pockets was found upstream of other flame wrinkles, preferentially near the highest magnitude flame curvatures. Different hypotheses for explaining this observation are discussed. The possibility of substantial heat release driven by auto-ignition and complicated diffusion has implications for reaction rate closure models and transport models used in turbulent combustion simulations.
\end{abstract}

Keywords: Flame/vortex interaction; turbulent premixed combustion; auto-ignition; laser Rayleigh scattering; hydrogen; differential diffusion.

\footnotetext{
${ }^{*}$ Corresponding author:

Email address: adam. steinbergeutoronto. ca (Adam M. Steinberg) 


\section{Introduction}

Whether chemical reactions progress through a flame-like or auto-ignition-like process is important for reaction rate closure models. Auto-ignition of homogeneous $\mathrm{H}_{2}$ /air systems is expected to occur for reactant temperatures at which the chain initiation reaction $\mathrm{H}_{2}+\mathrm{O}_{2} \stackrel{\mathrm{k} 1}{\rightarrow} \mathrm{HO}_{2}+\mathrm{H}$ produces $\mathrm{H}$ radicals at a sufficient rate that subsequent radical shuffle reactions (e.g. $\mathrm{H}+\mathrm{O}_{2} \stackrel{\text { k2 }}{\rightarrow} \mathrm{OH}+\mathrm{O}$ ) overcome recombination (e.g. $\left.\mathrm{H}+\mathrm{O}_{2}+\mathrm{M} \stackrel{k 3}{\rightarrow} \mathrm{HO}_{2}+\mathrm{M}\right)$ [1]. In homogeneous systems, this occurs at temperatures exceeding about $800 \mathrm{~K}$ due to the relatively slow chain initiation [2]. This paper reports the occurrence of repeatable auto-ignition in $\mathrm{H}_{2}$ /air mixtures at near-ambient local conditions - temperatures of approximately $350 \mathrm{~K}$ - upstream of curved flame surfaces during the interaction between a toroidal vortex and the flame. These auto-ignited pockets ultimately are responsible for a similar volumetric heat release rate as the original wrinkled flame.

The flame/vortex interaction configuration represents a fundamental unit problem in turbulent premixed combustion [3]. While practical turbulent combustion is not a superposition of isolated flame/vortex interactions [4], this configuration has proven useful in elucidating underlying processes and constructing models for the influence of practical turbulence through, e.g. stretch efficiency functions [5, 6]. Here, the flame/vortex interaction demonstrates the complex interaction between chemistry, transport, and unsteady fluid mechanics that can occur in turbulent flames and may not be captured in configurations that isolate kinetics or steady laminar flames.

In particular, the flame surface represents a source of heat and species that can influence the fluid upstream of the flame through diffusion and turbulent advection. Curved $\mathrm{H}_{2}$ /air flames are well known to cause spatial variations in radical concentration due to differential and thermal (Soret) diffusion, e.g. [7-17]. It generally is expected that relatively large $\mathrm{H}$ concentrations are confined to relatively high temperature regions of the flame due to rapid recombination at lower temperatures (via $\mathrm{H}+\mathrm{O}_{2}+\mathrm{M} \stackrel{\mathrm{k} 3}{\rightarrow} \mathrm{HO}_{2}+\mathrm{M}$ ), with differential and thermal diffusion leading to elevated (lowered) concentrations in regions of positive (negative) curvature. However, quantitative measurements of $\mathrm{H}$ concentrations using two-photon femtosecond laser induced fluorescence in lean laminar tubular $\mathrm{H}_{2}$ /air flames found that the $\mathrm{H}$ concentration could remain in the range of $2-5 \%$ of the peak value in regions with temperatures (measured using Raman scattering) less than about $400 \mathrm{~K}$
[14, 15]. These regions of elevated $H$ concentration occurred upstream of highly positively curved flames, and were not predicted by simulations employing detailed chemistry, multi-component diffusion, and the Soret effect. While auto-ignition was not observed, the tubular flame configuration involves a steady stretch rate (between 200-400 s ${ }^{-1}$ in Refs. [14, 15]) and is not perturbed by vortices.

The simultaneous presence of a flame and vortex also enables advection of other species that may help promote low-temperature ignition. DNS of $\mathrm{H}_{2}$ /air flames has shown that turbulence/flame interaction can transport $\mathrm{H}_{2} \mathrm{O}_{2}$ and $\mathrm{HO}_{2}$ well upstream of the high temperature regions [18]. For example, mass fractions of $\mathrm{HO}_{2}$ exceeding $40 \%$ of the maximum were found in regions with temperatures below $710 \mathrm{~K}$ in the DNS. The reaction rates of these species was notable even in the low temperature regions of the flow, which was attributed to low activation energy elementary reactions, though it was explicitly mentioned that auto-ignition could not occur in the DNS because the temperature was below $710 \mathrm{~K}$. The importance of these species in the second stage ignition of cool flames through branching at moderate temperatures was articulated by Reuter et al. [19]. While some branching rates (e.g. $\mathrm{H}_{2} \mathrm{O}_{2}+\mathrm{M} \rightarrow 2 \mathrm{OH}+\mathrm{M}$ ) are expected to be negligible at the temperatures of the ignition reported here, it is possible that relatively low concentrations of $\mathrm{H}$-atoms could significantly lower branching times because radical growth is initially exponential in time [20].

The objective of this paper is to demonstrate the ignition of $\mathrm{H}_{2}$ /air upstream of the flame, discuss its relationship with the fluid mechanics of flame/vortex interaction, and assess its potential impact.

\section{Experiment and Diagnostics}

Experiments were performed in the same single-jet stagnation flame configuration used by Thiesset et al. [6], shown in Fig. 11. The burner consisted of a flow straightener, reactant feed plenum, converging nozzle, and stagnation plate. Fuel $\left(\mathrm{H}_{2}\right)$ and air were metered using mass flow controllers (Brooks) and mixed well upstream of the burner at an equivalence ratio of $\phi=0.35$ (effective Lewis number of $L e=0.35$ ) [21]. The lean equivalence ratio was needed to prevent the flame from attaching to the nozzle. The upward-facing convergent nozzle (outflow diameter $D=15 \mathrm{~mm}$ ) created a laminar jet with a nearly top-hat velocity profile at the nozzle exit plane. Reactants were supplied at a total flow rate of 10 SLPM - corresponding to a bulk velocity of approximately $0.94 \mathrm{~m} / \mathrm{s}$ - and stagnated against the $4 \mathrm{~mm}$ thick 


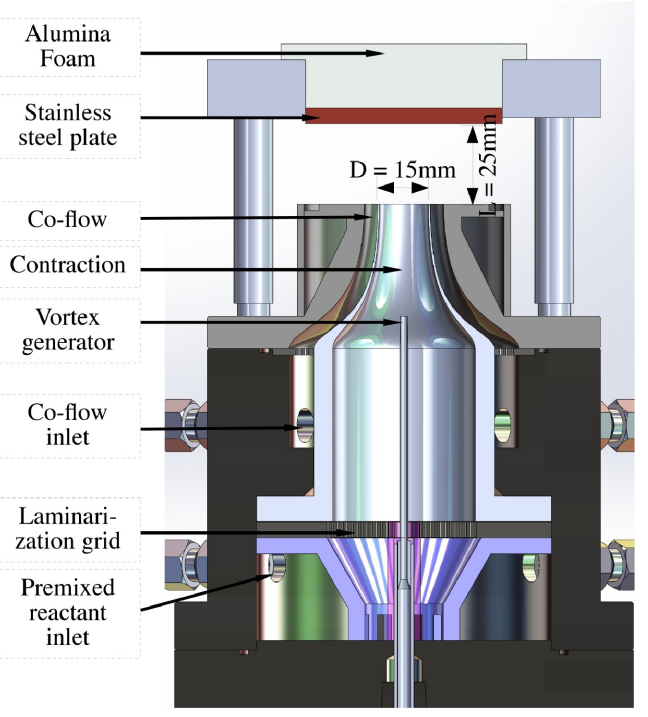

Figure 1: Burner schematic.

stainless-steel plate located $L=25 \mathrm{~mm}$ downstream. Under steady flow conditions (without the vortex), the flame stabilized approximately $10 \mathrm{~mm}$ downstream of the nozzle exit plane. The flame was isolated from the surrounding environment by a laminar nitrogen co-flow. The burner stagnation plate temperature was measured using IR thermometry and thermocouples in the unperturbed flame state. The maximum plate temperature was found to be $560 \mathrm{~K}$.

Highly-repeatable toroidal vortices were issued from a $2 \mathrm{~mm}$ diameter tube located on the centreline and ending $35 \mathrm{~mm}$ upstream the burner outlet. This tube was connected to a pressurized tank containing the same fuel/air mixture as the main flow. A vortex was generated by a well-controlled sudden discharge from the pressurized tank that was actuated using two electronically controlled and synchronized valves. The strength of the vortex was controlled by the pressure in the tank.

The particle image velocimetry (PIV) measurements of Theiesset et al. [6] are used herein to characterize the fluid mechanics in the reactants. The PIV measurements were obtained with a time resolution of $0.043 \mathrm{~ms}$, spatial resolution of $0.44 \mathrm{~mm}$, and vector spacing of $0.22 \mathrm{~mm}$. Figure 2 shows a typical vortex that occurs in this experiment. The vector arrows show $\vec{u}_{v}=\vec{u}-\vec{u}_{0}$, where $\vec{u}$ is the instantaneous measured velocity field and $\vec{u}_{0}$ is the velocity field prior to vortex injection. The vectors are overlaid on the out-of-plane vorticity field $\left(\omega_{z}\right)$. The vortex has a rotational velocity (based on a fit Oseen vortex) of approximately $1 \mathrm{~m} / \mathrm{s}$. The circumference of the toroidal vortex ring was approximately $3 \mathrm{~mm}$.

Gas-phase temperature data were obtained using laser

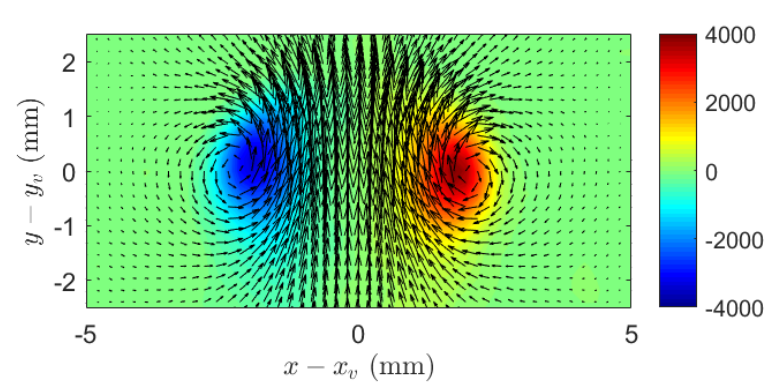

Figure 2: Typical vortex structure $\left(\vec{u}_{v}\right)$ measured by PIV in Ref. [6]. Background is out-of-plane vorticity $\left(\omega_{z}\right.$ in $\left.s^{-1}\right)$. Position is relative to the instantaneous vortex center $\left(x_{v}, y_{v}\right)$.

Rayleigh scattering (LRS) thermometry. The LRS measurements were phase-locked to 15 different times after the pressure discharge that produced the vortex, with a separation of $0.25 \mathrm{~ms}$ between phases. A single image at a single phase was captured per iteration of the flame/vortex interaction, with each phase being repeated three times.

LRS was generated from the pulsed second harmonic output of a Nd:YAG laser (Spectra Physics Lab 170), producing approximately $10 \mathrm{~ns}$ pulses with $430 \mathrm{~mJ} /$ pulse at $532 \mathrm{~nm}$. The laser output was formed into a sheet with a full-width-at-half-maximum of $80 \mu \mathrm{m}$ and a height of $12 \mathrm{~mm}$, which was transmitted along the center axis of the burner. The LRS signal was isolated from the broadband background using a $532 \mathrm{~nm}$ bandpass filter, and then collected using a camera lens (Tamron, $f=180 \mathrm{~mm}, f / \#=3.5$ ) and $\mathrm{sC}$ MOS camera (Andor Zyla) with an exposure time of $10 \mu \mathrm{s}$. Upstream of the burner, the LRS signal from a jet of clean room-temperature air was imaged onto a separate sCMOS camera, the signal from which was used to correct the burner LRS signal for shot-to-shot laser profile and intensity variations. Registration between the burner and sheet-correction cameras was performed by imaging the laser sheet through a uniform (non-reacting) fuel/air mixture issued through the cold burner at room temperature; this signal also was used as the reference in the LRS data inversion described below. Both cameras were corrected for the mean background and whitefield response. The data were $4 \mathrm{px} \times 4 \mathrm{px}$ binned to increase the signal-to-noise ratio, and filtered with a $10 \mathrm{px} \times 10 \mathrm{px}$ Wiener filter.

Inversion of the whitefield, background, and lasersheet corrected LRS signals $(S)$ to temperature was performed via

$$
T=T_{r e f} \frac{S_{r e f}}{S} \frac{(\partial \sigma / \partial \Omega)_{m i x}}{(\partial \sigma / \partial \Omega)_{m i x, r e f}}
$$




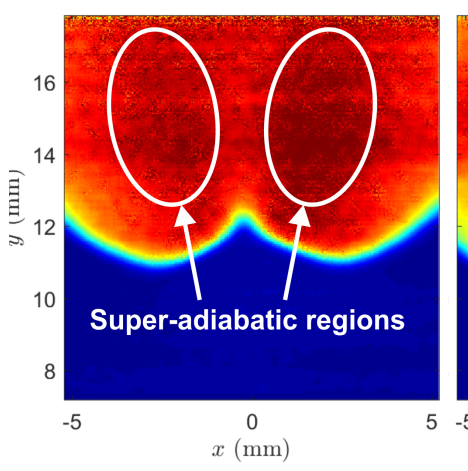

(a) Steady flame

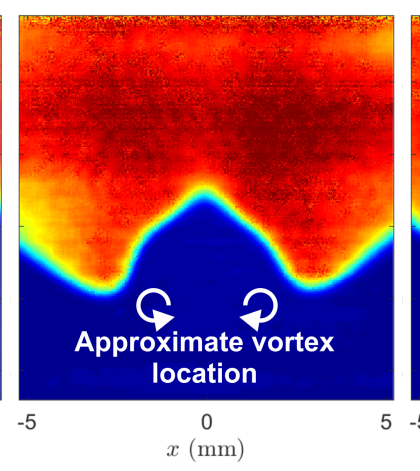

(b) Phase 2

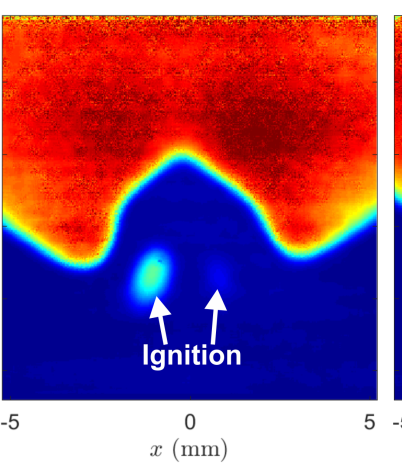

(c) Phase 4

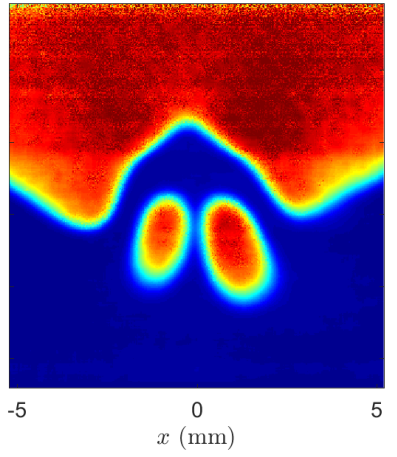

(d) Phase 5

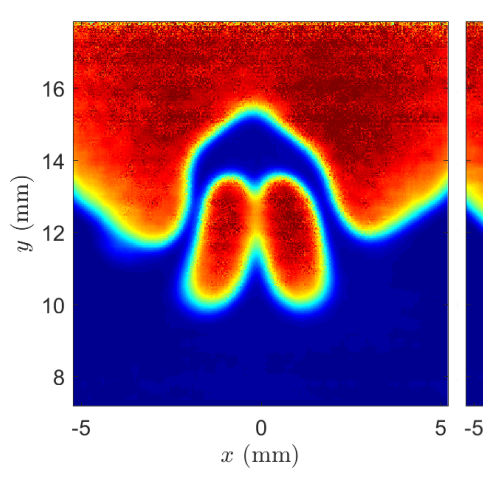

(e) Phase 6

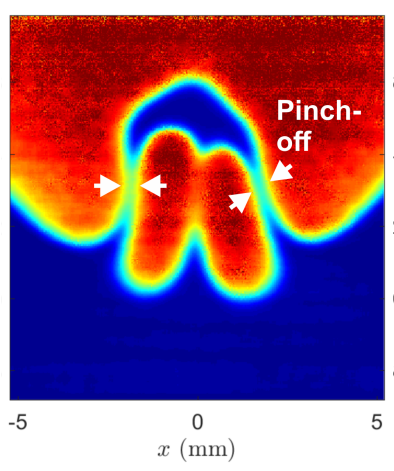

(f) Phase 7

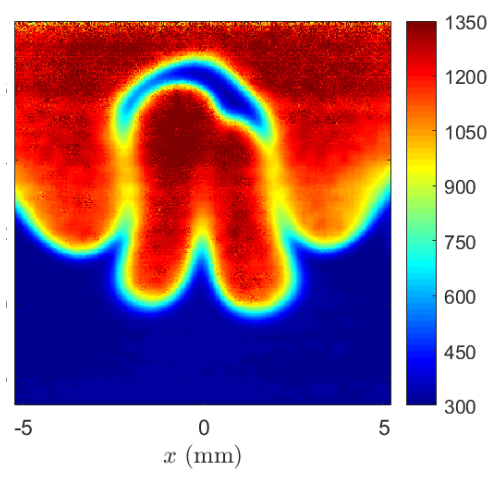

(g) Phase 8

Figure 3: Measured temperature fields $(\mathrm{K})$ at various phases during flame/vortex interaction. Ignition near the center ring of the toroidal vortex is seen at Phase 4. Time between phases is $0.25 \mathrm{~ms}$.

where subscript ref indicates a known reference case and $(\partial \sigma / \partial \Omega)_{m i x}$ is the differential Rayleigh scattering cross-section of the local mixture. The reference used here was the aforementioned non-reacting fuel/air mixture issued from the cold burner.

The mixture differential cross-section is a molefraction weighted average of the differential crosssections of the local species, which, for signal collection orthogonal to the polarization and propagation of the incident light, is

$$
\left(\frac{\partial \sigma}{\partial \Omega}\right)=\frac{4 \pi^{2}}{\lambda^{4}}\left(\frac{n-1}{N_{0}}\right)^{2}\left(\frac{3}{3-4 \rho_{p}}\right)\left(1+\rho_{p}\right)
$$

where $\lambda$ is the laser wavelength, $n$ is the index of refraction, $N_{0}$ is the Loschmidt number, and $\rho_{p}$ is the depolarization ratio [22, 23].

Here, the variation of composition with temperature was assumed to follow that of a laminar, premixed, $\phi=0.35 \mathrm{H}_{2}$ /air flame with a reactant temperature of $T_{r}$, calculated using the freely propagating flame model in Cantera with the chemical mechanism of Ref. [24].
The properties needed for evaluation of Eq. 2 were determined from Refs. [25.-27]. However, due to potential heating of the reactants associated with radiative heating of the burner nozzle, $T_{r}$ was unknown at the beginning of the calculation. An iterative procedure therefore was implemented, in which the LRS temperature field first was computed using the cross-section versus temperature map for a $T_{r}=290 \mathrm{~K}$ flame, the actual $T_{r}$ determined from the data, and then the LRS temperature field recomputed using the map from this new $T_{r}$. Due to the relatively constant cross-section in this lean-premixed flame and low preheating, this procedure converged after two iterations at $T_{r}=310 \mathrm{~K}$.

The signal-to-noise ratio was determined to be approximately 18 and 9 in the reactants and products, respectively. Uncertainty in the temperature was dominated by the shot-noise. Assuming Poisson statistics for the noise, the temperature uncertainty (based on standard deviation) was $8 \mathrm{~K}$ and $60 \mathrm{~K}$ in the reactants and products, respectively. The higher uncertainty in the products arises due to increased sensitivity of the signalto-temperature inversion at higher temperatures. This 
shot-noise uncertainty is expected to manifest as random high-frequency fluctuations.

\section{Results and Discussion}

\subsection{Observation of auto-ignition and subsequent flame propagation}

Figure 3 shows a sequence of measured temperature fields at different phases after the vortex injection. These images are typical of all measured vortex passages. Prior to the vortex interaction, the flame exhibited a cellular structure with a stable negative curvature region (concave towards reactants) centered over the burner centerline. The vortex began interacting with the flame at Phase 2 after the injection, forming a larger wrinkle in the flame surface that was comprised of a small region of high-magnitude negative curvature surrounded by larger regions of lower magnitude positive curvature. The effects of differential diffusion are apparent in the products of Fig. 3, which show decreased (increased) temperature downstream of the negatively (positively) curved flame region. Super-adiabatic temperatures are reached, in the range of $1350 \mathrm{~K}$ compared to an adiabatic flame temperature of $1310 \mathrm{~K}$.

At Phase 4 in Fig. 3 elevated temperature regions appeared well upstream of the flame surface in the vicinity of highest positive curvature (Phase 3 is omitted since it is visually similar to Phase 2 ). Two such regions formed at approximately equal distances on either side of the burner centerline. As will be discussed below, the locations of these regions correspond to the intersection of the toroidal vortex ring with the measurement plane at a radial location towards the center relative of the peak vorticity. The peak temperatures in the left and right regions were approximately $780 \mathrm{~K}$ and $410 \mathrm{~K}$, respectively, for the particular flame/vortex interaction shown, which are well below the adiabatic flame temperature. This represents auto-ignition in the center of the vortex ring. The asymmetry is due to minor stochastic imperfections in the flame and vortex, along with the sensitivity of the ignition process.

Subsequent to the ignition, an outwardly propagating toroidal flame formed. The upper surface of the toroidal flame and the original flame flame propagated towards each other, rapidly consuming the intervening reactants. The geometry of the wrinkled and toroidal flames resulted in a pocket of unburnt reactants being pinched off by flame collisions at Phase 7. This pocket was subsequently consumed by an inwardly propagating flame.

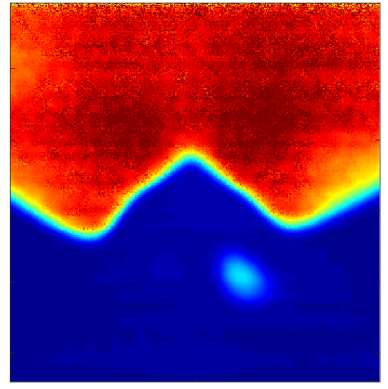

(a)

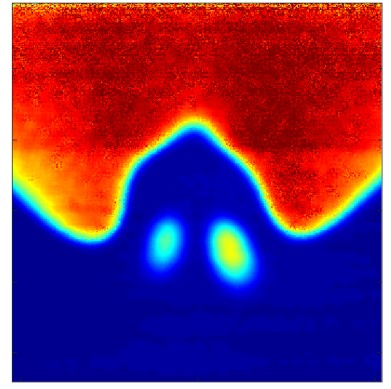

(b)
Figure 4: Additional examples of the initial auto-ignition time, demonstrating the lack of connection to the main flame. Scales and colormap as in Fig. 3

\subsection{Auto-ignition versus $3 D$ flame}

An alternative explanation of the observed elevated temperature regions at Phase 4 in Fig. 3 is that there is a connection between the main flame and the toroidal vortex at some unobserved out-of-plane location. However, this explanation is unlikely since the flame/vortex interaction pushes the main flame away from the vortex center. Furthermore, no such connection was observed in any iteration of the experiment at phases prior to the outwardly expanding toroidal flame merging with the main flame (around Phase 7). For example, Fig. 4 shows two additional auto-ignition events with detached ignition pockets near the center of the vortex ring. The temperatures measured in such small detached pockets were all well below the adiabatic flame temperature, again supporting ignition over a 3D flame.

Based on the image sequence in Fig. 3, auto-ignition would result in a region of elevated temperature separated from the main flame over approximately Phases 4-6. Figure 5 shows the minimum distance $\left(d_{\min }\right)$ between various (relatively low-temperature) iso-therms of the main-flame and the upstream region of elevated temperature at these phases. The line represents the mean over all iterations of the experiment, and the errorbars represent the standard deviation. Three iso-therms are presented because the temperature captured at the measurement instant near the beginning of the ignition (Phase 4) varied between iterations of the experiment. A connected flame would result in a zero-separation, which would greatly affect the mean distance. The initial auto-ignition at Phase 4 was over $1 \mathrm{~mm}$ upstream of iso-therms of the main flame. The distance decreased steadily over time due to the outward expansion of the toroidal flame after ignition. The above arguments demonstrate that the observed pockets are due to autoignition, not out-of-plane flame propagation. 


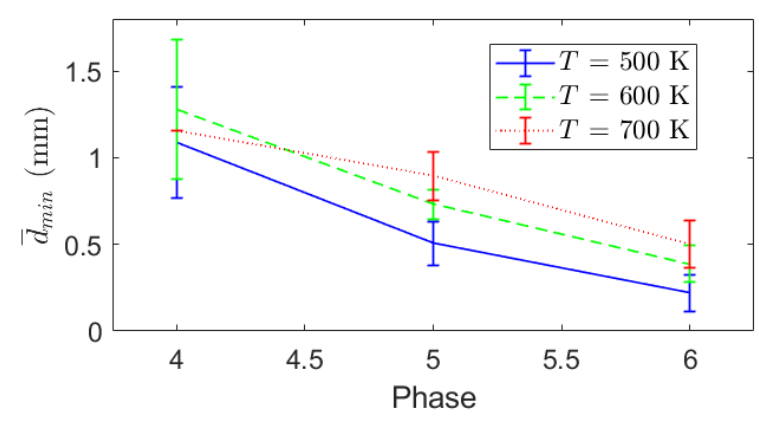

Figure 5: Mean over experimental iterations of the minimum distance between various iso-therms in the main flame and the upstream region of elevated temperature versus phase. Errorbars indicate standard deviation over iterations.

\subsection{Ignition relative to fluid mechanics}

Figure 6 shows the position of the ignition sites relative to the vorticity field, $2 \mathrm{D}$ dissipation-rate field $\left(\varepsilon / v=\epsilon_{i j} \epsilon_{i j}\right)$, and shear strain-rate field $\left(\epsilon_{x y}\right)$, where $\epsilon_{i j}=1 / 2\left(\partial_{j} u_{i}+\partial_{i} u_{j}\right)$. The fluid dynamic fields are taken at the same instant after vortex injection as the ignition occurred and the position is centered at the vortex location.

The ignition sites occurred towards the centerline relative to the locations of peak vorticity, dissipation rate, strain-rate. It is particularly notable that the ignition consistently occurred in a region of low dissipation that was immediately inboard and below a region of high dissipation. This low-dissipation region is farther away from the flame surface than other regions of the vortex, which are expected to contain more reactive mixtures. Furthermore, Fig. 3 shows that the subsequent outward expansion of the toroidal flame occurred faster in the axial direction than the radial direction. The shape of the $\epsilon_{x y}$ field indicates that this evolution occurs preferentially along direction of low strain-rate. These results highlight the importance of the local fluid-dynamic strain-rate on the ignition process, and are consistent with the requirement for increased spark-ignition energy with increased turbulent dissipation, e.g. [28, 30].

The results of Shim et al. [18] indicate that $\mathrm{H}_{2} \mathrm{O}_{2}$ and $\mathrm{HO}_{2}$ may be advected from the flame by the vortex, through a region of high dissipation rate, to the inboard side of the toroidal vortex. The timescale of this advection was estimated by placing a theoretical Lagrangian particle at the center of the ignition sites and tracing its position backward through time (using a fourth-order Runge-Kutta method) until its minimum distance to the flame. The calculated advective time scale was approximately $0.5 \mathrm{~ms}$, which corresponds well to the time between the beginning of the flame/vortex interaction (at Phase 2) and the observed ignition (0.5 ms later at Phase

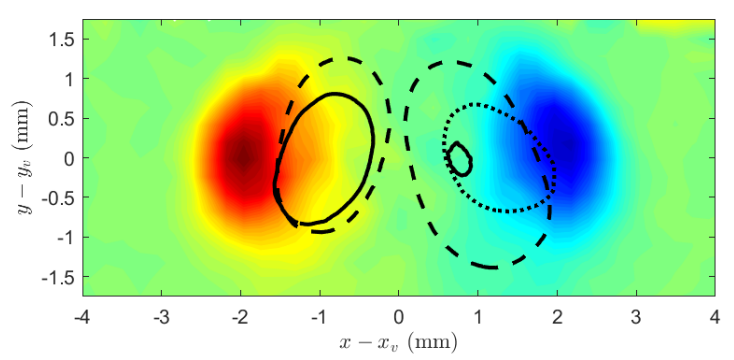

(a) $\omega_{z}$, color scale from -4000 to $4000 \mathrm{~s}^{-1}$.

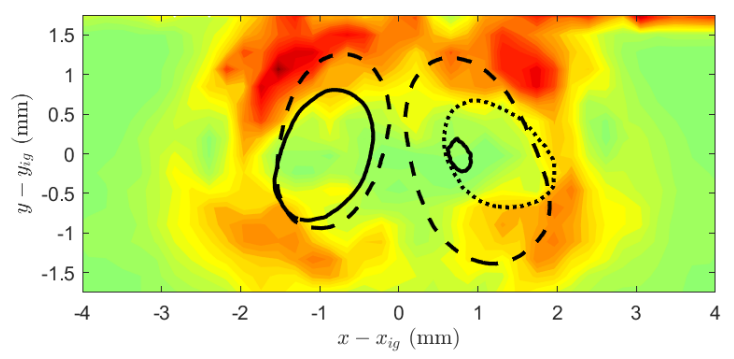

(b) $\varepsilon / v$, color scale from $-2 \times 10^{6}$ to $2 \times 10^{6} \mathrm{~s}^{-2}$.

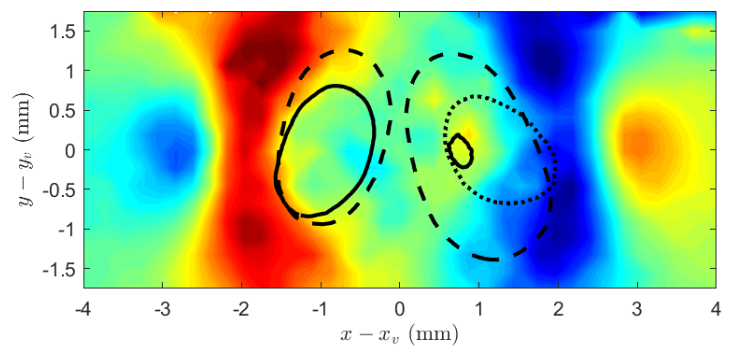

(c) $\epsilon_{x y}$, color scale from -800 to $800 \mathrm{~s}^{-1}$.

Figure 6: Correspondence of ignition locations with fluid mechanical fields. (-) - Fig. 3 c), ( . .) - Fig.4 a), (- -) - Fig.4b). Colorbar as in Fig. 2

4).

Despite the low strain-rate, branching of these species at the measured temperature would require the presence of additional radicals. The measurements of Hall et al. [14, 15] indicate that H-radicals can be present upstream of positively curved flame surfaces at these temperatures and distances. We therefore hypothesize that $\mathrm{H}_{2} \mathrm{O}_{2}$ and $\mathrm{HO}_{2}$ are advected by flame/vortex interaction to a region of low strain-rate that - since it lies upstream of a positively curved flame surface - has sufficient $\mathrm{H}$ to initiate branching.

\subsection{Heat release rate resulting from auto-ignition}

Given that auto-ignition can occur upstream of curved $\mathrm{H}_{2}$ /air flame surfaces, it is necessary to assess its potential impact. From Fig. 3 it is clear that the outwardly expanding toroidal flame that results from the 


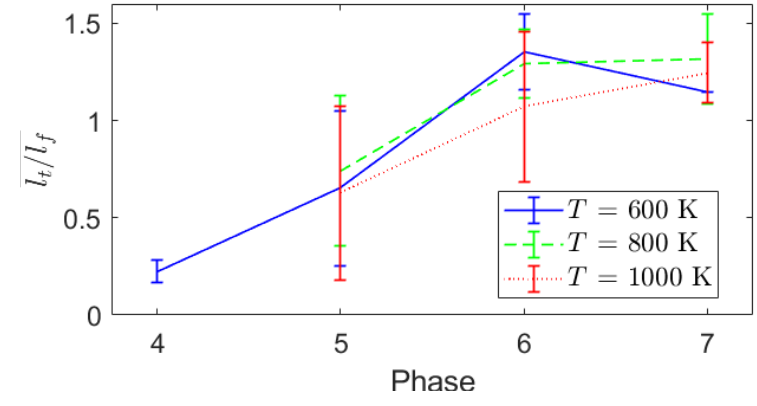

Figure 7: Ratio of length of various iso-therms in the toroidal flame to main flame as a function of phase during flame/vortex interaction. Errorbars represent the standard deviation across iterations of the experiment.

initial auto-ignition pockets is responsible for a significant fraction of the conversion of reactants to products. To quantify this, the length of different iso-therms in the main flame $\left(l_{f}\right)$ and expanding toroidal flame $\left(l_{t}\right)$ were calculated. Different iso-therms were studied to address any ambiguities around the time of flame merging. The region of interest is confined to $-5 \mathrm{~mm}<x<5 \mathrm{~mm}$.

Figure 7 shows the mean $l_{t} / l_{f}$ over Phases $4-7$, which were the phases after ignition and prior to flame merging. The toroidal flame was longer than the wrinkled main flame after Phase 6, and already was comparable to the main flame at Phase 5. Assuming an axisymmetric flame with an area that is approximately proportional to the in-plane measured flame length, and assuming an approximately constant heat release rate per unit area, the toroidal flame resulting from the auto-ignition would approximately double the volumetric heat release rate during the flame/vortex interaction. Note that equating heat release with flame area likely is inaccurate during the initial ignition process at Phase 4.

\subsection{Ignition away from the toroidal vortex}

The toroidal vortex is the location at which ignition was most repeatable and the possibility of 3D flame effects can be eliminated with the most confidence. However, several similar ignition events occurred in other regions of the cellular wrinkled flame. Figure 8 shows examples of two such events. In total, $85 \%$ of the acquired images after Phase 4 showed evidence of auto-ignition away from the primary flame/vortex interaction, with many images containing multiple auto-ignition pockets. It therefore can be deduced that auto-ignition upstream of the curved main flame occurs quite readily.

The locations favorable for ignition were evaluated based on the curvature of the main flame $(\kappa)$. Here, only early stage ignition kernels were considered, which were defined to be detached kernels with a maximum temperature of less than $800 \mathrm{~K}$. For each such kernel,
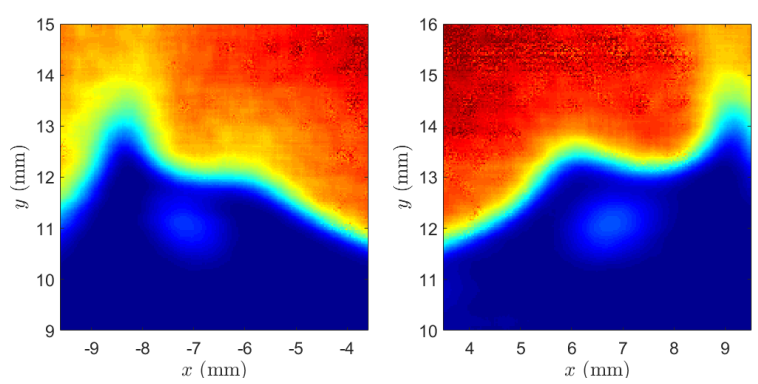

Figure 8: Other examples of auto-ignition events away from the toroidal vortex. Colormap as in Fig. 3 .

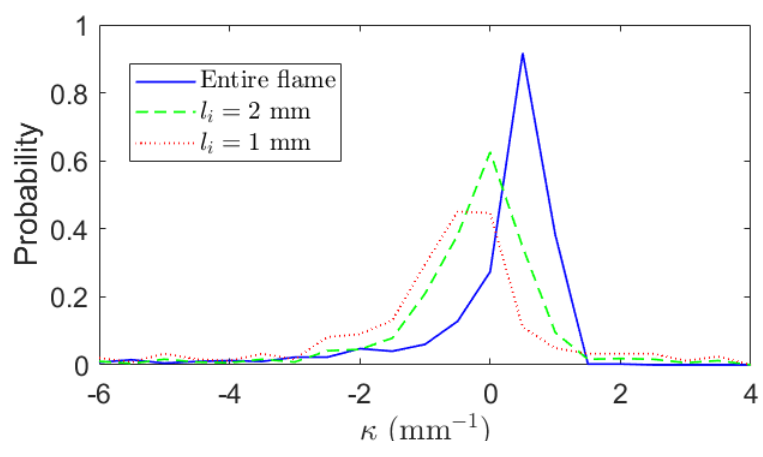

Figure 9: Probability density functions of main flame curvature over the entire flame surface, and in proximity to ignition kernels.

the closest point between the main flame and the kernel centroid was determined. The statistics of the main flame curvature in different regions around this point were then compiled. Curvature was calculated on the $T=600 \mathrm{~K}$ isotherm. Effects of pixelation on the calculation were removed using a third-order spline smooth.

Figure 9 shows the probability density functions of the curvature for the entire main flame, as well as in regions centered $l_{i}=1 \mathrm{~mm}$ and $2 \mathrm{~mm}$ around the point identified above. The curvature of the main flame was as expected, with high probability of lowmagnitude positive curvature and smaller probability of high-magnitude negative curvature. Ignition occurred near flame wrinkles, as indicated by the increased probability of high-magnitude curvature (both positive and negative) with closer proximity to the kernel.

\subsection{Discussion}

Given the relative propensity of this system to autoignite, the lack of previous similar observations warrants consideration. Very few premixed flame/vortex interaction experiments have been performed using $\mathrm{H}_{2}$ [31, 32]. This likely is because of the confounding effect of the cellular instability on quantities typically of interest in flame/vortex experiments, such as flame stretch rates. However, Di Sarli et al. [32] used PIV 
to study the interaction of toroidal vortices with $\mathrm{H}_{2}$ /air flames. Aerosol olive oil seed was used, which evaporated at a particular temperature. Various figures in their work show pockets of low seed density in the reactants, typically at locations of vortex centers that are a short distance upstream of highly curved flame segments. This could be evidence of ignition.

In experiments with turbulent flames, measurements often are made with diagnostics that would not detect the early stage of ignition (e.g. OH or CH PLIF); pockets may merge with the flame prior to their being detected. Furthermore, the presence of isolated burning pockets in the reactants measured using planar diagnostics generally is attributed to 3D flame surface orientations. The results presented here bring this interpretation into question and demonstrate the need for 3D scalar diagnostics.

\section{Conclusion}

This paper demonstrates the ignition of reactants at near-ambient temperatures, upstream of curved $\mathrm{H}_{2}$ /air flame surfaces during flame/vortex interaction. Multiple iterations of the experiment demonstrated repeated ignition at distances approximately $1 \mathrm{~mm}$ upstream of the flame. The ignition occurred in a region of low dissipation rate that was farther away from the flame surface than other locations with less favorable fluid mechanics for ignition. The auto-ignited pockets ultimately led to an approximate doubling of the volumetric heat release rate during the flame/vortex interaction.

The potential of auto-ignition as a significant heat release pathway in turbulent premixed flames at moderate reactant temperatures has significant implications for reaction rate closure models, stressing the importance of turbulent species advection and low-temperature finiterate chemistry. Furthermore, the hypothesized presence of $\mathrm{H}$ radicals well upstream of the flame - which may be required for low-temperature branching - demonstrates the importance of accurate transport modeling. Future work should attempt to measure $\mathrm{HO}_{2}, \mathrm{H}_{2} \mathrm{O}_{2}$, and $\mathrm{H}$ during flame/vortex interactions, and also attempt to identify this behavior in turbulent flames.

\section{Acknowledgements}

This work was supported by NSERC under RGPIN2017-06501, an Ontario Research Fund Early Researcher Award, and the French Government Program 'Investissements d'avenir' through the LABEX CAPRYSSES ANR-11-LABX-0006-01.

\section{References}

[1] P. Boivin, A. L. Sánchez, F. A. Williams, Combust. Flame 106 (2013) 76-82.

[2] A. L. Sánchez, F. A. Williams, Prog. Energy Combust. Sci. 41 (2014) 1-55.

[3] P. Renard, D. Thevenin, J. Rolon, S. Candel, Prog. Energy Combust. Sci. 26 (2000) 225-282.

[4] A. M. Steinberg, J. F. Driscoll, Combust. Flame 156 (2009) 2285-2306.

[5] O. Colin, F. Ducros, D. Veynante, T. Poinsot, Phys. Fluids 12 (2000) 1843-1863.

[6] F. Thiesset, G. Maurice, F. Halter, N. Mazellier, C. Chauveau, I. Gokalp, Proc. Combust. Inst. 36 (2017) 1843-1851.

[7] A. Ern, V. Giovangigli, Combust. Theor. Model. 2 (1998) 349372.

[8] H. Im, J. Chen, Combust. Flame 131 (2002) 246-258.

[9] Y.-C. Chen, R. Bilger, Combust. Flame 138 (2004) 155-174. Cited By 46.

[10] Y. Dong, A. Holley, M. Andac, F. Egolfopouos, S. Davis, P. Middha, H. Wang, Combust. Flame 142 (2005) 374-387.

[11] F. Yang, C. K. Law, C. J. Sung, H. Q. Zhang, Combust. Flame 157 (2010) 192-200.

[12] J. F. Grcar, J. B. Bell, M. S. Day, Proc. Combust. Inst. 32 (2009) 1173-1180.

[13] M. Day, J. Bell, P.-T. Bremer, V. Pascucci, V. Beckner, M. Lijewski, Combust. Flame 156 (2009) 1035-1045. Cited By 66.

[14] C. A. Hall, W. D. Kulatilaka, J. R. Gord, R. W. Pitz, Combust. Flame 161 (2014) 2924-2932.

[15] C. A. Hall, W. D. Kulatilaka, N. Jiang, J. R. Gord, R. W. Pitz, Proc. Combust. Inst. 35 (2015) 1107-1114.

[16] R. Barlow, M. Dunn, G. Magnotti, Combust. Flame 162 (2015) 727-735. Cited By 2.

[17] A. J. Aspden, Proc. Combust. Inst. 36 (2017) 1997-2004.

[18] Y.-S. Shim, N. Fukushima, M. Shimura, Y. Nada, M. Tanahashi, T. Miyauchi, Proc. Combust. Inst. 34 (2013) 1383-1391.

[19] C. B. Reuter, S. H. Won, Y. Ju, Proc. Combust. Inst. 36 (2017) 1513-1522.

[20] P. Boivin, A. L. Sánchez, F. A. Williams, Combust. Flame 176 (2017) 489-499.

[21] N. Bouvet, F. Halter, C. Chauveau, Y. Yoon, Int. J. Hydrog. Energy 38 (2013) 5949-5960.

[22] R. Miles, W. Lempert, J. Forkey, Meas. Sci. Technol. 12 (2001) R33-R51.

[23] M. Boguszko, G. Elliott, Prog. Aerosp. Sci. 41 (2005) 91-143.

[24] A. Keromnes, W. K. Metcalfe, K. A. Heufer, N. Donohoe, A. K. Das, C.-J. Sung, J. Herzler, C. Naumann, P. Griebel, O. Mathieu, M. C. Krejci, E. L. Petersen, W. J. Pitz, H. J. Curran, Combust. Flame 160 (2013) 995-1011.

[25] W. Gardiner Jr., Y. Hidaka, T. Tanzawa, Combust. Flame 40 (1981) 213-219.

[26] J. Fielding, J. Frank, S. Kaiser, M. Smooke, M. Long, Proc. Combust. Inst. 29 (2002) 2703-2709.

[27] J. Sutton, J. Driscoll, Opt. Lett. 29 (2004) 2620-2622.

[28] C. Cardin, B. Renou, G. Cabot, A. M. Boukhalfa, Combust. Flame 160 (2013) 1414-1427.

[29] S. S. Shy, C. C. Liu, W. T. Shih, Combust. Flame 157 (2010) 341-350.

[30] S. F. Ahmed, R. Balachandran, E. Mastorakos, Proc. Combust. Inst. 31 (2007) 1507-1513.

[31] T. Lee, J. Lee, D. Nye, D. Santavicca, Combust. Flame 94 (1993) 146-160.

[32] V. Di Sarli, A. Di Benedetto, E. J. Long, G. K. Hargrave, Int. J. Hydrog. Energy 37 (2012) 16201-16213. 